\title{
Structural and Dielectric Study of a PLNZNT Ceramic Material Doped with Chromium
}

\author{
Sadok Hadjadj ${ }^{1 *}$, Ahmed Boutarfaia ${ }^{2}$, Louiza Zenkhri ${ }^{3}$ \\ ${ }^{1}$ Lab. Rayonnement et Plasmas et Physique de Surfaces, Université K.M, Ouargla 30 000, Algeria \\ ${ }^{2}$ Laboratoire de chimie appliquée, 2 Univ Biskra, Fac. des Sc Exactes S.N.V, Biskra 07 000, Algeria \\ ${ }^{3}$ Département de Chimie, Fac. Des Mathématiques et des Sciences de la Matière, Université K.M, Ouargla 30 000, Algeria
}

Corresponding Author Email: hadjadjsadok@gmail.com

https://doi.org/10.18280/acsm.430201

Received: 5 January 2019

Accepted: 10 March 2019

\section{Keywords:}

perovskites, doped PZT, dielectric, XRD, dielectric response

\begin{abstract}
The purpose of this work is to show the effect of Chromium $(\mathrm{Cr})$ on the

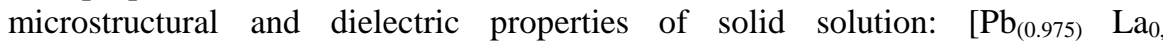
$\left.{ }_{015} \mathrm{Nd}_{0.01}\right]\left[\left(\mathrm{Zr}_{0,524} \mathrm{Ti}_{0,476)}{ }_{(0.9875-(\mathrm{w} / 4)}\right) \mathrm{Nb}_{0.005} \mathrm{Cr}_{\mathrm{w}} \mathrm{O}_{3}\right]$ with $\mathrm{w}=0.0,0.5,1.0,2.5$ and 5.0 molar \% (abbreviated PLNZNCT) were developed by solid state chemical reaction. The analysis by X-ray diffraction and the calculation of the tolerance factor $(\mathrm{t})$ show a stable single-phase perovskite structure of tetragonal symmetry sintered at $1200^{\circ} \mathrm{C}$. The SEM micrograph, the density test and the dielectric measurements indicate that the PLNZNCT ceramic achieves optimal values at $1 \mathrm{~mol} \% \mathrm{Cr} 3+$. These obtained results, perhaps characterize the classic hard ferroelectric materials.
\end{abstract}

\section{INTRODUCTION}

The dielectric ceramics $\mathrm{Pb}(\mathrm{Zr}, \mathrm{Ti}) \mathrm{O}_{3}$, abbreviated (PZT) are very sensitive oxides to insertion or substitution at site $\mathrm{A}$ (and / or) site $\mathrm{B}$, because of their simple perovskite $\mathrm{ABO}_{3}$ structure. The purpose of doping is often related to the improvement of ceramic properties for their industrial applications (sensors, actuators and resonators) [1]. The properties of solid solutions with perovskite structure can be modified either by a cationic (and/or) anionic change according to the different substitutions and the different stages of development [2]. Doping of ions $\left(\mathrm{La}^{3+}, \mathrm{Nd}^{3+}\right)$ at site $\mathrm{A}\left(\mathrm{Pb}^{2+}\right)$ and ions $\left(\mathrm{Nb}^{5+}, \mathrm{Cr}^{3+}\right)$ at site $\mathrm{B}\left(\mathrm{Zr}^{4+} / \mathrm{Ti}^{4+}\right)$ can change the properties of solid solutions (PZT) in order to obtain PLNZNCT ceramic from the complex perovskite structure $\left(\mathrm{AA}^{\prime} \mathrm{BB}^{\prime} \mathrm{O}_{3}\right)$ of the high performance [3]. The best electrical properties can be located around the concentration zone of $\mathrm{x}=52.4$ for $\mathrm{PLNZNT}$ ceramic $\left[\mathrm{Pb}\left(\mathrm{Zr}_{\mathrm{x}}, \mathrm{Ti}_{(1-\mathrm{X})}\right) \mathrm{O}_{3}\right.$ doped with $1.5 \mathrm{~mol} \% \mathrm{La}, 1 \mathrm{~mol} \% \mathrm{Nd}$ and $0.5 \mathrm{~mol} \% \mathrm{Nb}$ ] can be used in piezoelectric applications for the manufacture of sensors and motors [4]. Studies with other rare earth oxides are very limited. Therefore; in this work the $\mathrm{Cr}^{3+}$ element was chosen as a dopant to determine their effect on crystalline structure and dielectric properties for PLNZNT ceramic. Formulas and chemical compositions have been presented in Table 1 [2].

Table 1. Stoichiometric PLNZNCT ceramic compositions synthesized

\begin{tabular}{|c|}
\hline General Formula: $\left[\mathrm{Pb}_{(1-(\mathrm{x}+\mathrm{y}))} \mathrm{La}_{x} \mathrm{Nd}_{\mathrm{y}}\right]\left[\mathrm{Zr}_{0.524} \mathrm{Ti}_{0.476}\right]_{(1-\mathrm{x} / 4-\mathrm{y} / 4-(5 z / 4)-(3 \mathrm{w} / 4))} \mathrm{Nb}_{\mathrm{z}} \mathrm{Cr}_{\mathrm{w}} \mathrm{O}_{3}$ \\
\hline Chemical Formula: $\left[\mathrm{Pb}_{0.975} \mathrm{La}_{0.015 \mathrm{Nd} 0.01}\right]\left[\mathrm{Zr}_{0.524} \mathrm{Ti}_{0.476}\right]_{(0.9875-3 \mathrm{w} / 4)} \mathrm{Nb}_{0.005} \mathrm{CrwO}_{3}$ \\
\hline with: $\mathrm{x}=0.015, \mathrm{Y}=0,01$ and $\mathrm{z}=0.005$ \\
\hline $\mathrm{w}=0.00 \mathrm{~mol} \% \quad\left[\mathrm{~Pb}_{0.975} \mathrm{La}_{0.015} \mathrm{Nd}_{0.01}\right]\left[\mathrm{Zr}_{0.524} \mathrm{Ti}_{0.476}\right]_{0.9875} \mathrm{Nb}_{0.005} \mathrm{O}_{3}$ \\
\hline $\mathrm{w}=0.50 \mathrm{~mol} \% \quad\left[\mathrm{~Pb}_{0.975} \mathrm{La}_{0.015} \mathrm{Nd}_{0.01}\right]\left[\mathrm{Zr}_{0.524} \mathrm{Ti}_{0.476}\right]_{0.9837} \mathrm{Nb}_{0.005} \mathrm{Cr}_{0.005} \mathrm{O}_{3}$ \\
\hline $\mathrm{W}=1.00 \mathrm{~mol} \% \quad\left[\mathrm{~Pb} 0_{0.975} \mathrm{La} 0.015 \mathrm{Nd} 0.01\right]\left[\mathrm{Zr}_{0.524} \mathrm{Ti}_{0.476}\right]_{0.980} \mathrm{Nb}_{0.005} \mathrm{Cr}_{0.01} \mathrm{O}_{3}$ \\
\hline$\left[\mathrm{Pb} 0_{0.975} \mathrm{La}_{0.015} \mathrm{Nd}_{0.01}\right]\left[\mathrm{Zr}_{0.524} \mathrm{Ti}_{0.476}\right]_{0.9687} \mathrm{Nb}_{0.005} \mathrm{Cr}_{0.025} \mathrm{O}_{3}$ \\
\hline$\left[\mathrm{Pb}_{0.975} \mathrm{La}_{0.015} \mathrm{Nd}_{0.01}\right]\left[\mathrm{Zr}_{0.524} \mathrm{Ti}_{0.476}\right]_{0.9500} \mathrm{Nb}_{0.005} \mathrm{Cr}_{0.050} \mathrm{O}_{3}$ \\
\hline
\end{tabular}

\section{EXPERIMENTATION}

\subsection{Treatment of ceramics}

In order to develop the desired material (PLNZNCT), commercial oxides of $99 \%$ purity were used as powder base product ( $\mathrm{PbO}, \mathrm{La}_{2} \mathrm{O}_{3}, \mathrm{Nd}_{2} \mathrm{O}_{3}, \mathrm{ZrO}_{2}, \mathrm{Nb}_{2} \mathrm{O}_{5}, \mathrm{Cr}_{2} \mathrm{O}_{3}$ et $\mathrm{TiO}_{2}$ ). The latter were synthesized with solid state reaction method at high temperature. After grinding and compaction in the form of cylindrical pellets, the obtained PLNZNCT solid solution were calcined at $930{ }^{\circ} \mathrm{C}$ with a heating rate of $5{ }^{\circ} \mathrm{C} / \mathrm{min}$ for 2 hours. This operation reduces the size of the grains and increases the reactivity PLNZNCT ceramic. The calcined powders were regrinded and compacted in the form of a disk of diameter $13 \mathrm{~mm}$ and $1.5 \mathrm{~mm}$ thick, and then treated at $1200{ }^{\circ} \mathrm{C}$ with a heating rate of $2{ }^{\circ} \mathrm{C} / \mathrm{min}$ for 3 hours in order to complete the crystallization and increase the density of the material. The volatility of lead oxide $(\mathrm{PbO})$ during sintering makes this material non-stoichiometric so it is important to add small amounts of $\mathrm{PbZrO}_{3}$ to minimize the loss of $\mathrm{PbO}$ oxide 
and to improve the dielectric properties of the final product [56]. To measure the dielectric properties, the electrodes were made by applying a silver paste on the two main faces of sintered pellets, followed by a heat treatment at $500{ }^{\circ} \mathrm{C}$ for 3hours [5].

\subsection{Relative density and porosity measurement}

Density is a physical quantity that influences the structural and electrical properties of ceramics. The relative density D (compactness) is given by the equation (1) of the material PLNZNCT sintered at $1200^{\circ} \mathrm{C}$ :

$$
D=\frac{\rho \exp }{\rho \mathrm{th}}
$$

such that:

$\rho_{\text {exp: }}$ the experimental density calculated from the mass and the volume of fritted ceramics pellet.

$\rho_{\text {th }}$ : the theoretical density obtained from the X-ray diffraction database providing the mesh parameters.

To verify the densification of the ceramic, the porosity $(\mathrm{P})$ of the pellets were measured by the equations (2) [5]:

$$
P=1-\frac{\rho \exp }{\rho \mathrm{th}}=1-D
$$

\subsection{Structural characterization}

An X-ray Diffractometer (XRD), D8 ADVANCE type (BRUKER-AX) with $\mathrm{Cu}-\mathrm{K} \alpha_{1}=1.5406 \AA$ filtered radiation was used to characterize the crystal structure of the sintered samples. The scan was recorded in the range of $2 \theta$ varies from 5 to $85^{\circ}$ with a scanning speed of $2^{\circ} / \mathrm{min}$.

\subsection{SEM microstructure analysis}

In order to study the microstructure of elaborate PLNZNCT samples, SEM images were obtained using a JEOL JSM63901v scanning electron microscope.

\subsection{Dielectric characterization}

The dielectric constant and the dissipation factor $(\tan \delta)$ were measured using an HP/Agilent 4284A RCL-meter impedance bridge at a temperature ranging from $30{ }^{\circ} \mathrm{C}$ to $500{ }^{\circ} \mathrm{C}$.

\section{RESULTS AND DISCUSSION}

\subsection{X-ray diffraction studies}

Figure1 illustrates X-ray diffraction patterns for $\mathrm{Cr}^{3+}$ doped PLNZNT ceramics. The results of the XRD for the samples under our study show a peak formation: (101) and (110), (002) and (200), (102) and (201), (112) and (211) were produced at $2 \theta=30.930^{\circ}$ and $31.351^{\circ}, 43.828^{\circ}$ and $44.978^{\circ}, 49.735^{\circ}$ and $50.486^{\circ}$ and $54.992^{\circ}$ and $55.743^{\circ}$, respectively correspond to a pure perovskite structure of tetragonal phase [7]. According to Hardtl and Hennings, it is estimated that $\left(\mathrm{La}^{3+} / \mathrm{Nd}^{3+}\right)$ ions replace partially the $\mathrm{Pb}^{2+}$ ion at site $\mathrm{A}$ by producing defects site B. The ions $\left(\mathrm{Nb}^{5+} / \mathrm{Cr}^{3+}\right)$ partially replace the $\left(\mathrm{Zr}^{4+} / \mathrm{Ti}^{4+}\right)$ ions at site $\mathrm{B}$ to maintain the charge balance of the tetragonal structure. A good distribution of the gaps (lacunes) ensures the equilibrium of the electric charges at site A (and / or) at site B in order to obtain the electro-neutrality of the perovskite of the PZT ceramic [8].
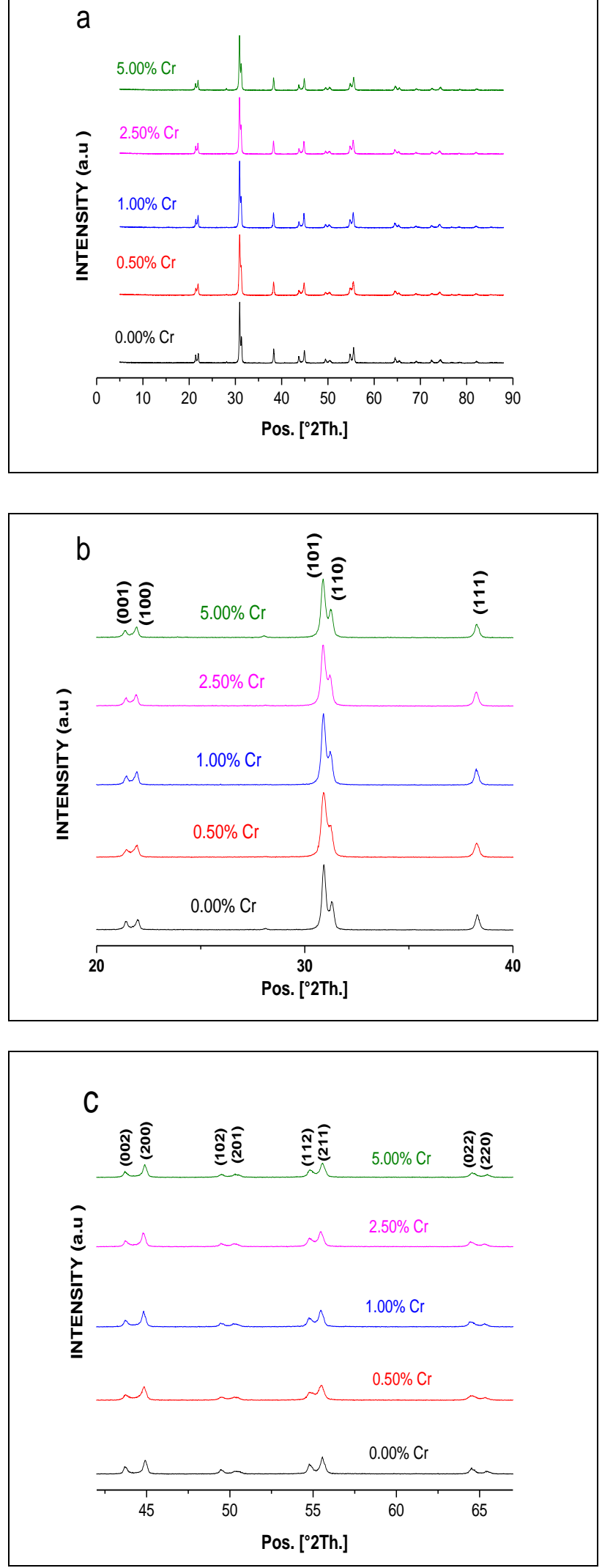

Figure 1. Representative X-ray diffraction of Cr-doped PLNZNT ceramic at the $2 \theta$ from: a $-05^{\circ}$ to $90^{\circ}$ b $-20^{\circ}$ to $40^{\circ}, \mathrm{c}-40^{\circ}$ to $70^{\circ}$ 
The mesh parameters obtained from the PLNZNCT ceramics in Table 2, undergo expansion and then condensation in the direction of the (ат) axis and also a small variation between the mesh parameters (ат, $\mathrm{cT}$ ). The tetragonality ratio (c/a) changes with the chromium oxide substitution, which does not typically affect the tetragonality of the network structure.

Table 2. Structural parameters calculated from the XRD data

\begin{tabular}{lllll}
\hline $\mathbf{C r}(\mathbf{w})$ & $\mathbf{a}=\mathbf{b}\left(\mathbf{A}^{\circ}\right)$ & $\mathbf{c}\left(\mathbf{A}^{\circ}\right)$ & $\mathbf{c} / \mathbf{a}$ & $\mathbf{V}_{\left(\mathbf{A}^{\circ}\right)^{\mathbf{3}}}$ \\
\hline 00.00 & 4.02811 & 4.01289 & 0.99622 & 66.9951 \\
\hline 0.005 & 4.03423 & 4.12018 & 1.02130 & 67.056 \\
\hline 0.010 & 4.03587 & 4.12452 & 1.02196 & 67.1812 \\
\hline 0.025 & 4.03506 & 4.12137 & 1.02139 & 67.1029 \\
\hline 0.050 & 4.02317 & 4.12001 & 1.02407 & 66.6860 \\
\hline
\end{tabular}

\subsection{Microstructural study of ceramics}

To study the microstructural characteristics of PLNZNCT ceramic materials, SEM scanning electron microscopy is used to determine the most compacted structure. Figure 2 shows that the studied samples have a microscopic structure consisting of granules of different shapes and sizes. The grain boundary is compact and the appearance of pores is very low. Generally larger grains correspond to higher dielectric properties. At high size, homogeneous distribution and more dense grain was observed at 1 molar $\% \mathrm{Cr}$ ratio. But changing this concentration will result in a decrease in grain size and affect negatively the dielectric properties, due to the deterioration of the microstructure [9].
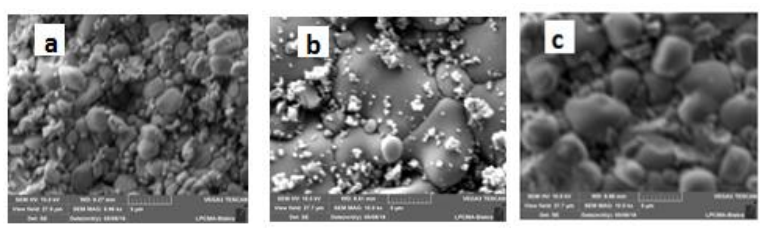

Figure 2. SEM micrographs of PLNZNCT ceramics with different amounts of $\mathrm{Cr}$ sintered for $2 \mathrm{~h}$ at $1200{ }^{\circ} \mathrm{C}(\mathrm{a}=0.5$; $\mathrm{b}$

\subsection{Tolerance factor}

$$
=1 ; \mathrm{c}=2.5) \mathrm{Cr} \%
$$

The stability of the perovskite structure (ABO3) is characterized by the tolerance factor $(\mathrm{t})$ which determines the compactness and freedom of movement of cations A and B. According to Goldschmidt, the structure is stable if $0.88<t$ $<1.09$, but it exhibits a distortion in the stability of the structure beyond this range. The tolerance factor $(\mathrm{t})$ could be determined by the following formula:

$$
t=\frac{\sum R a+R o}{\sqrt{2\left(\sum R b+R o\right)}}
$$

where: $\sum \mathrm{Ra}, \sum \mathrm{Rb}$ and Ro are respectively the ionic radii of cations; A, B and Oxygen [10]. The perovskite structure is more stable when the tolerance factor $(\mathrm{t})$ is close to 1 . The involved bonds play a strong ionic character [11]. The perovskite range showed a constant orientation with a slight constant change $(\Delta t)$ of 0.00063 in tolerance values $(t)$ [12]. According to the results in Table 3 it can be concluded that PLNZNT becomes more and more stable with the increase of the chromium content.
Table 3. Tolerance factor (t) of PLNZNCT ceramics

\begin{tabular}{ccc}
\hline Cr.mol \% & Tolerance(t) & Variation $(\Delta \mathbf{t})$ \\
\hline 0 & 0.918546 & $/ /$ \\
\hline 0.005 & 0.9191832 & 0.0006372 \\
\hline 0.01 & 0.9198213 & 0.0006381 \\
\hline 0.025 & 0.921741 & 0.0019197 \\
\hline 0.05 & 0.9249583 & 0.0032173 \\
\hline
\end{tabular}

\subsection{Relative density and porosity}

Table 4 shows the variations in relative density and porosity of PLNZNCT ceramic sintered at $1200{ }^{\circ} \mathrm{C}$ as a function of $\mathrm{Cr}$ concentration. It is distinguished that the PLNZNT ceramic doped with $1 \mathrm{~mol} \%$ of $\mathrm{Cr}$ reaches a maximum value of the apparent density and minimum value of the porosity. The high values of the density and the low values of the porosity confirm a disappearance of the pores, a reduction of the volume of the crystalline mesh and a more compact structure [13].

Table 4. The density and porosity of PLNZNT ceramics according to the rate of $\mathrm{Cr}$

\begin{tabular}{ccccc}
\hline $\mathbf{C r}(\mathbf{w})$ & $\begin{array}{c}\boldsymbol{\rho} \text { th } \\
\left(\mathbf{g} / \mathbf{c m}^{\mathbf{3}}\right)\end{array}$ & $\begin{array}{c}\boldsymbol{\rho} \exp \\
\left(\mathbf{g} / \mathbf{c m}^{\mathbf{3}}\right)\end{array}$ & $\mathbf{D} \%$ & $\mathbf{1 - D}$ \\
\hline 0 & 8.02683 & 7.51050 & 93.567646 & 0.06044 \\
\hline 0.005 & 8.00544 & 7.55357 & 94.355481 & 0.05645 \\
\hline 0.01 & 7.9674 & 7.66444 & 96.197612 & 0.03803 \\
\hline 0.025 & 7.9696 & 7.46776 & 93.702069 & 0.06298 \\
\hline 0.05 & 7.9222 & 7.41952 & 93.654784 & 0.06346 \\
\hline
\end{tabular}

\subsection{Dielectric characterization}

The two Figures, 3(a, b) and 4(a, b) give the experimental results, the measurements of the dielectric parameters including the dielectric constant (cr) and the dissipation factor $(\tan \delta)$ of the PLNZNCT ceramic sintered at $1200{ }^{\circ} \mathrm{C}$, at the frequency of $1 \mathrm{kHz}$ depending on the temperature.

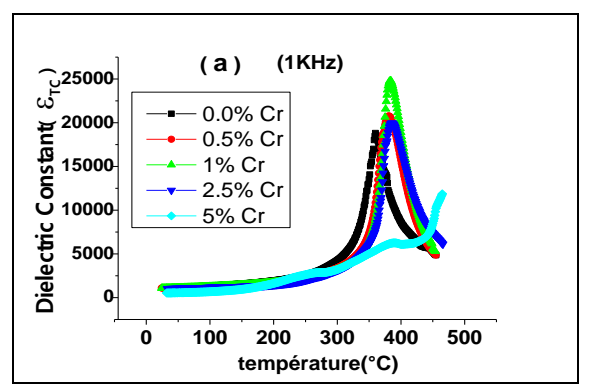

(a) Dielectric constant $\left(\varepsilon_{\mathrm{r}}\right)$

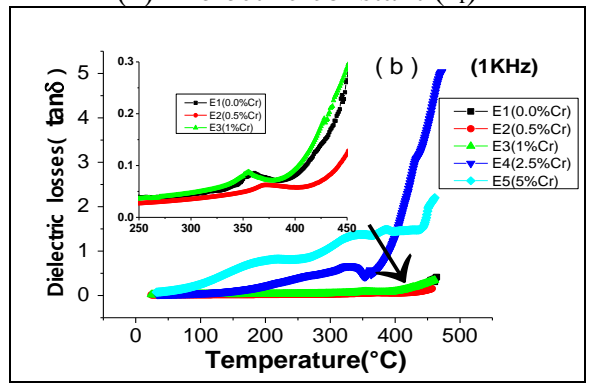

(b) Dielectric losses $(\tan \delta)$

Figure 3. Influence of the temperature in the dielectric proprietys ( $\mathrm{a}-\varepsilon \mathrm{r}$ and $\mathrm{b}-\tan \delta$ ) of the PLNZNCT ceramics 


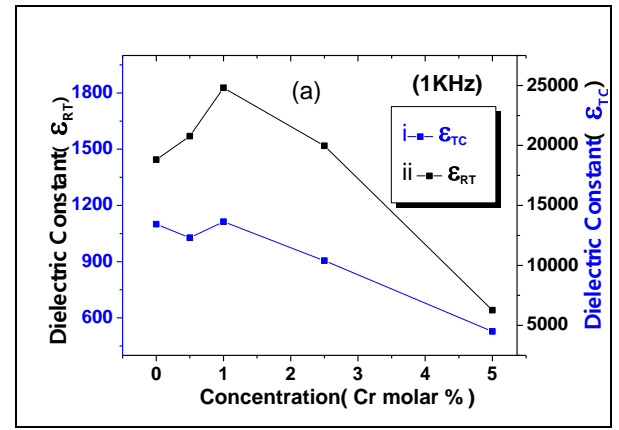

(a) Dielectric constant (i $-\varepsilon_{\mathrm{TC}}$, ii $\left.-\varepsilon_{\mathrm{RT}}\right)$

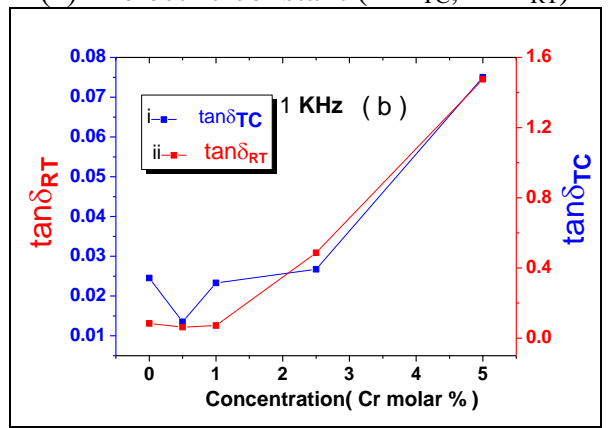

(b) Dielectric losses (i- $\tan \delta_{\mathrm{TC}}$, ii- $\tan \delta_{\mathrm{RT}}$ )

Figure 4. Influence of the $\mathrm{Cr}$ ratio in the dielectric propertys (cr and $\tan \delta$ ) at: (i) - room temperature (R.T), (ii)- transition temperature (T.C) for PLNZ NCT ceramics

According to previous studies, the doping of the acceptor ions in the perovskite crystal lattice decreases the dielectric constant and increases the curie temperature (Tc) [14]. The strongest dielectric response is that associated with the doped sample of $1 \mathrm{~mol} \% \mathrm{Cr}$. The dielectric losses reach minimum values, for PLNZNT ceramic doped with; $0.0,0.5$ and 1 molar \% of Cr, comparing with PLNZNT ceramic doped with 2.5 and 5 molar \% of $\mathrm{Cr}$ [15]. Above the phase transition temperature, the dielectric losses of the PLNZNCT ceramic increase strongly and constantly throughout the series. This leads to the increase in conductivity, which could be due to the electro-dipolar polarization of $\mathrm{Cr}$-doped PLNZNT ceramics [16].

The increase in PLNZNCT ceramic dielectric constant doped with $1 \%$ chromium may also be due to the multiple donor cations $\left(\mathrm{La}^{3+}, \mathrm{Nd}^{3+}\right.$ at site $\mathrm{A}$ and $\mathrm{Nb}^{3+}$ at site $\left.\mathrm{B}\right)$ and the $\mathrm{Cr}^{3+}$ acceptor cations at site B [17]. The dielectric properties for the different systems studied have been summarized in Table 5 [18].

Table 5. Critical values of the dielectric properties of PLNZNT doped with Cr

\begin{tabular}{cccccc}
\hline $\begin{array}{c}\mathbf{C r} \\
\text { molar\% }\end{array}$ & $\boldsymbol{\varepsilon}_{\mathbf{R T}}$ & $\operatorname{tn} \boldsymbol{\delta}_{\mathbf{R T}}$ & $\begin{array}{c}\mathbf{T}_{\mathbf{C}} \\
\left({ }^{\circ} \mathbf{C}\right)\end{array}$ & $\begin{array}{c}\boldsymbol{\varepsilon}_{\mathbf{m a x}} \\
(\mathbf{T})\end{array}$ & $\mathbf{t n \boldsymbol { \delta } _ { \mathbf { T c } }}$ \\
\hline 0.0 & 1099.72 & 0.0245 & 360 & 18811.66 & 0.0840 \\
\hline 0.5 & 1027.84 & 0.0135 & 381 & 20772.64 & 0.0626 \\
\hline 1.0 & 1113.21 & 0.0233 & 383 & 24805.80 & 0.0721 \\
\hline 2.5 & 904.77 & 0.0267 & 385 & 19965.95 & 0.4865 \\
\hline 5.0 & 527.59 & 0.0750 & 390 & 6259.96 & 1.4756 \\
\hline
\end{tabular}

\subsubsection{Variation of the dielectric constant $\left(\varepsilon_{\mathrm{r}}\right)$}

Figure $5(a, b)$ illustrates the effect of the frequency on the dielectric constant ( $\varepsilon r$ ) of the PLNZNT ceramic doped with 1 mole $\% \mathrm{Cr}$ sintered at $1200^{\circ} \mathrm{C}$ as a function of temperature. It can be seen that the curves of (Er) pass through the same stage and reach maximum values at the transition temperature of the ferro - paraelectric phase. Therefore the PLNZNCT ceramic belongs to the classic ferroelectric material family hard, this perhaps explains the diminution of the dielectric permittivity above the Curie temperature (Tc) [19]. It has been observed that the dielectric constant decreases with the increase of the frequency, which can be attributed to the existence of different types of decreasing polarization [17].

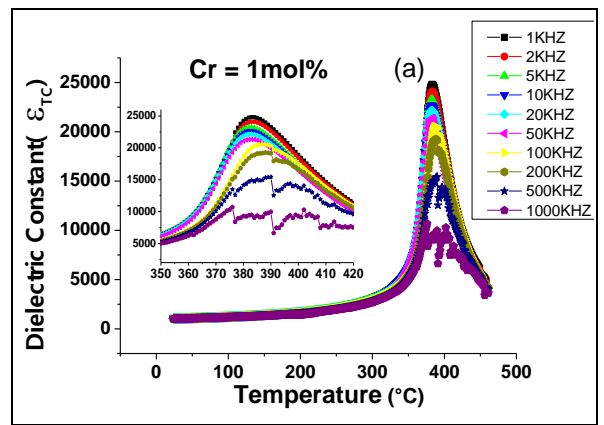

(a) Dielectric constant $\left(\varepsilon_{\mathrm{r}}\right)$

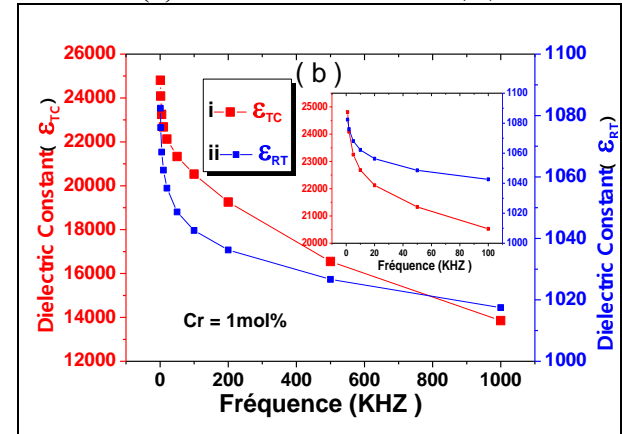

(b) Dielectric constant (i - $\varepsilon_{\mathrm{TC}}$, ii $\left.-\varepsilon_{\mathrm{RT}}\right)$

Figure 5. Influence of Frequency in the constant dielectric (er) for 1molar\% PLNZNCT Ceramics at: (i) - room temperature (R.T), (ii)- transition temperature (T.C)

\subsubsection{Evolution of the dissipation factor $(\tan \delta)$}

Figure $6(a, b)$ shows the effect of the frequency on the dissipation factor $(\tan \delta)$, which plays an important role in the high frequency circuits of the PLNZNT ceramics doped with 1 molar \% of $\mathrm{Cr}$ and sintered at $1200{ }^{\circ} \mathrm{C}$, depending on the temperature. It is seen that the maximum values of dielectric loss in the vicinity of the transition temperature (Tc) decreases as the frequency increases to $20 \mathrm{KHz}$; then they increase with the increase of the frequency from $50 \mathrm{KHz}$ up to $1000 \mathrm{KHz}$, this is due to the movements of the dipole moments. The increase in temperature causes a deterioration of the properties of the material and distortion of the structure, which are related to the movement of the walls of the domains [20]. The dissipation factor is associated with a rate of electrical energy loss, often in the form of dissipated heat [21].

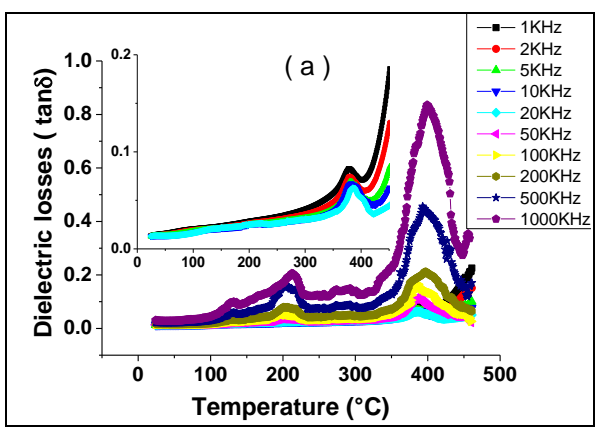

(a) Dielectric losses $\left(\tan \delta_{\mathrm{TC}}\right)$ 


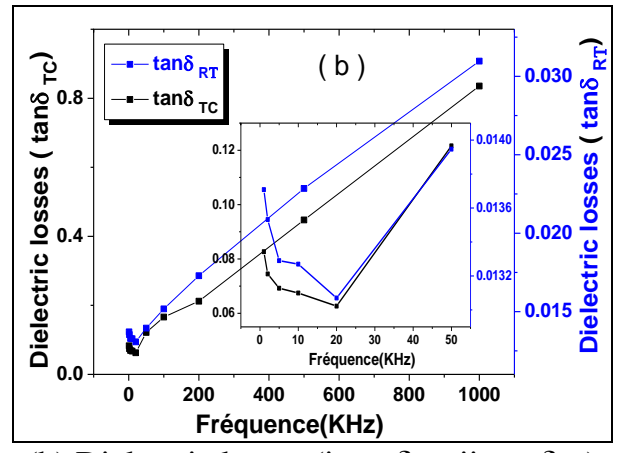

(b) Dielectric losses (i- $\tan \delta_{\mathrm{TC}}$, ii- $\tan \delta_{\mathrm{RT}}$ )

Figure 6. Influence of Frequency in the dissipation Factor ( $\tan \delta)$ for 1 molar\% PLNZNCT Ceramics at: (i) - room temperature (R.T), (ii)- transition temperature (T.C)

\section{CONCLUSION}

Solid solutions of the type $\left[\mathrm{Pb}_{0.975} \mathrm{La}_{0.015} \mathrm{Nd}_{0.01}\right]\left[\mathrm{Zr}_{0.524} \mathrm{Ti}\right.$ $\mathbf{0 . 4 7 6}_{(0.9875-3 w / 4)} \mathrm{Nb}_{0.005} \mathrm{CrwO}_{3}$ with $\mathrm{w}=0.0,0.5,1.0,2.5$ and 5.0 molar \% abbreviated PLNZNCT were synthesized by the conventional solid state method, sintered at $1200{ }^{\circ} \mathrm{C}$. The Xray diffraction pattern in the range of $05^{\circ}$ to $85^{\circ}$ shows that all compositions have a pure crystallized perovskite structure. The multilayer surface PLNZNCT at 1 molar\% Cr ratio shows homogeneous uniform grain distributions in the SEM image. The calculation of the tolerance factor ( $t$ ) of PLNZNCT material can confirm the stability of the perovskite structure. The doped sample of 1 molar\% of $\mathrm{Cr}$ shows a denser microstructural development $\left(7.6644 \mathrm{~g} / \mathrm{cm}^{3}\right)$, less porous (0.03803) and a higher dielectric permittivity (24805.8) at the transition temperature $\left(\mathrm{Tc}=383{ }^{\circ} \mathrm{C}\right)$ during sintering. The reduction of the dielectric constant and the dielectric loss with the increase of the frequency is due to the movements of the dipole moments, which explain the existence of the different types of polarization. Increasing the rate of chromium in PLNZNT ceramics is often associated with loss of electrical energy due to the growth of conductivity, resulting in deterioration of material properties that are related to the movement of the domain walls. According to the results of this study, PLNZNCT ceramic, considered a hard-ferroelectric material, can be used at different frequencies in several technological fields.

\section{ACKNOWLEDGMENT}

The author sincerely wishes to thank Professor Hamadi Khemakhem of the University of Sfax (Tunisia), Professor Mohamed Abou-Salam of the Mohammed Premier University of Oujda (Morocco) and Professor Mohammed Tayeb Meftah of the Kasdi Merbah University of Ouargla (Algeria) for their technical assistance, support and valuable suggestions extended during this work.

\section{REFERENCES}

[1] Zahi, S., Bouaziz, R., Abdessalem, N., Boutarfaia A. (2003). Dielectric and piezoelectric properties of $\mathrm{PbZrO}_{3}-\mathrm{PbTiO}_{3}-\mathrm{Pb}\left(\mathrm{Ni}_{1 / 3}, \mathrm{Sb}_{2 / 3}\right) \mathrm{O}_{3}$ ferroelectric ceramic system. Ceramics International, 29(1): 35-39.
https://doi.org/10.1016/S0272-8842(02)00086-X

[2] Kondo, M., Hida, M., Omote, K., Taniguchi, O., Mita, T., Umemiya, S., Kurihara, K. (2003). Preparation of $\mathrm{PbNi}_{1 / 3} \mathrm{Nb}_{2 / 3} \mathrm{O}_{3}-\mathrm{PbTiO}_{3}-\mathrm{PbZrO}_{3}$ ceramic mu / ltilayer actuator with silver internal electrodes. Sensors and Actuators A: Physical, 109(1-2): 143-148. https://doi.org/10.1016/S0924-4247(03)00357-1

[3] Simon, L. (2002). Elaboration et caractérisation de films épais piézoélectriques sérigraphies sur alumine, silicium, aciers inoxydables et vitrocéramiques, Thèse de doctorat en Electronique et Electrotechnique, INSA- lyon (France).

[4] Ramam, K., Lopez, M. (2008). Dielectric, ferroelectric and piezoelectric studies of neodymium-modified PLZNT ceramics for sensor and actuator applications Journal of Alloys and Compounds, 466(1-2): 466-466. https://doi.org/10.1016/j.jallcom.2007.11.055

[5] Lejeune, M., Boilot, J.P. (1986). Optimization of dielectic properties of lead-magnesium niobate ceramics. American Ceramic Society Bulletin, 65(4): 679-682. https://doi.org/10.1111/j.1151-2916.1986.tb04780.x

[6] Wamh, H., Schulze, W.A. (1990). The role of excess Magnesium oxyde or Lead oxide in determining the microstructure and properties of Lead Magnesium Niobate. Journal of the American Ceramic Society, 73(4): 825-832. 2916.1990.tb05121.x https://doi.org/10.1111/j.1151-

[7] Murakami, S., Herren, M., Rau, D., Sakurai, T., Morit, M., Lumin, J. (1999). Low-temperature luminescence and energy transfer processes in $\mathrm{Eu}^{3+}, \mathrm{Nd}^{3+}$, and $\mathrm{Cr}$ doped sol-gel PLZT ceramics. Journal of Luminescence, 83-84: 215-219. https://doi.org/10.1016/S00222313(99)00101-5

[8] Hardtl, K.H., Hennings, D. (1972). Distribution of A-site and B-site vacancies in ( $\mathrm{Pb}, \mathrm{La})(\mathrm{Ti}, \mathrm{Zr}) \mathrm{O}_{3}$ ceramics. J. Am. Ceram. Soc. https://doi.org/10.1111/j.1151-2916.1972.tb11267.x

[9] Jin, B.M., Lee, D.S., Kim, I.W., Kwon, J.H., Lee, J.S., Song, J.S., Jeong, S.J. (2004). The additives for improving piezoelectric and ferroelectric properties of $0.2 \mathrm{~Pb}\left(\mathrm{Mg}_{1 / 3} \mathrm{Nb}_{2 / 3}\right) \mathrm{O}_{3}-0.8\left[\mathrm{PbZr} \mathrm{O}{ }_{3}-\mathrm{PbTiO}_{3}\right]$ ceramics. Ceramics International 30(2004): 1449-1451. https://doi.org/10.1016/j.ceramint.2003.12.070

[10] Soares, M.R., Senos, A.M.R., Mantas, P.Q. (2000). Phase coexistence region and dielectric properties of PZT ceramics. Journal of the European Ceramic Society, 20(3): 321-334. https://doi.org/10.1016/S09552219(99)00170-3

[11] Pauling, L. (1967). The nature of chemical bonds. New York: Cornell University Press, 267. https://books.google.dz/books?id=SCghAQAAIAA.

[12] Dean, J.A. (1985). Lange's Handbook of Chemistry, $13^{\text {th }}$ edn. McGraw Hill, New York. https://www.abebooks.com/Lange/2744356110/bd

[13] Galasso, F.S. (1969). Structure, Properties and Preparation of Perovskite -type Compounds, Pergamon Press, Oxford. https://searchworks.stanford.edu/view/11605327

[14] Su'arez-G'omez, A., Durruthy M.D. (2008). Properties of the PLZTN $x / 54 / 46(0.4 \leq x \leq 1.4)$ ceramic system. Materials Research Bulletin, 44(5): 1116-1121. https://doi.org/10.1016/j.materresbull.2008.10.002

[15] Ramam, K., Chandramouli, K. (2011). Dielectric and piezoelectric properties of rare-earth gadolinium 
modified lead lanthanum zirconium niobium titanate ceramics. Ceramics International, 37: 979-984. https://doi.org/10.1016/j.ceramint.2010.11.016

[16] Fan, H., Kim, H.E. (2002). Perovskite stabilization and electromechanical properties of polycrystalline lead zinc niobate-lead zirconate titanate. Journal of Applied Physics, 91(1):

317-322. https://doi.org/10.1063/1.1421036

[17] Xu, Y. (1991). Ferroelectric Materials and Their Applications, North Holland, Amsterdam, 110-150. www.gbv.de/dms/ilmenau/toc/022310215.PDF.

[18] Tiwari, V. (2015). Geetika srivastava the effect of $\mathrm{Li}_{2} \mathrm{CO}_{3}$ addition on the structural, dielectric and piezoelectric properties of PZT ceramics. Ceramics International, 41(2B): 2774-2778 https://doi.org/10.1016/j.ceramint, 2014/10/096
[19] He, Z., Ma, J., Zhang R., Li, T. (2003). PZT-based materials with bilayered structure: preparation and ferroelectric properties. Journal of the European Ceramic Society, 23(2003):

1943-1947. https://doi.org/10.1016/S0955-2219(02)00423-5

[20] Nowick, A.S., Berry, B.S., Katz Lawrence, J. (1972). Anelastic relaxation in crystalline solids. Journal of Applied Mechanics, 42(3): 659-669. https://doi.org/10.1115/1.3423694

[21] Demirezen, S., Kaya, A., Yeris_kin, S.A., Balbas, M., Uslu, S.I. (2016). Frequency and voltage dependent profile of dielectric properties, electric modulus and ac electrical conductivity in the $\mathrm{PrBaCoO}$ nano fiber capacitors. Results in Physics, 6: 180-185. http://doi.org/10.1016/j.rinp.2016.03.00 